\title{
Age-dependent penetrance of different germline mutations in the BRCA1 gene
}

\author{
F Al-Mulla, ${ }^{1}$ J M Bland, ${ }^{2}$ D Serratt, ${ }^{3}$ J Miller, ${ }^{3}$ C Chu, ${ }^{3}$ G T Taylor ${ }^{4}$
}

\begin{abstract}
- Additional data are published online only at http://jcp.bmj. com/content/vol62/issue4

${ }^{1}$ Department of Pathology, Molecular Pathology Unit, Faculty of Medicine, Safat, Kuwait; ${ }^{2}$ Department of Health Sciences, University of York, York, UK; ${ }^{3}$ Yorkshire Regional Genetics Service, St James's Hospital, Leeds, UK; ${ }^{4}$ St James's Hospital Leeds, Genomic Services, Institute for Cancer Research, Cancer Research UK
\end{abstract}

Correspondence to:

Dr Fahd Al-Mulla, Department of Pathology, Molecular Pathology Unit, Faculty of Medicine, PO

Box 24923, Safat, Kuwait 13110; fahd@al-mulla.org

Accepted 11 November 2008

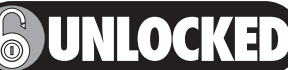

This paper is freely available online under the BMJ Journals unlocked scheme, see http:// jcp.bmj.com/info/unlocked.dtl

\section{ABSTRACT}

Aims: BRCA1 gene mutations have been extensively studied in relation to breast and ovarian cancer susceptibility. Various genotype-phenotype correlation attempts have yielded important data pertaining to the consequences of BRCA1 mutations. However, little is known about the effects of recurrent BRCA mutations on expressivity and the age of onset of cancer in a population. This study addresses whether different exon mutations have variable expressivity especially in relation to the age of onset of breast cancer.

Methods: Using a step-wise systematic approach, culminating in the sequencing of all BRCA1 and BRCA2 exons with the addition of multiplex ligation-dependent probe amplification, the relationship between disease phenotypes and gene mutations in 219 individuals and their family members was examined.

Results: It is shown that different BRCA1 gene mutations have distinct effects that influence the age of onset of breast or ovarian cancer. Mutations in exon 2 of the BRCA1 gene had significantly lower penetrance compared with mutations of exons 11, 13 and 20. The median age of affliction with breast cancer was 55 years for 185delAG in exon $2(95 \%$ confidence interval (CI) 46.7 to 59.5), 47 years for the 4184delTCAA mutation in exon 11 (95\% Cl 39 to 55.4), and 41 years for exon 13 duplication (95\% Cl 32.9 to 49.7) of the BRCA1 gene. Moreover, 14 novel mutations in BRCA1 and BRCA2 genes in the Yorkshire/Humberside population were identified. Conclusions: The 185delAG mutation of the BRCA1 gene is a low penetrance mutation that is age dependent especially when compared with the exon 13 duplication mutation. The data have important ramifications on screening, genetic counselling and prophylactic treatment of BRCA1 gene mutation carriers.

Breast cancer is the most prevalent malignancy in women. ${ }^{1}$ In the western hemisphere the lifetime risk of developing breast cancer is more than $10 \%$. Ovarian cancer, on the other hand accounts for a lifetime risk of $1.8 \%{ }^{2}$ The majority of breast and ovarian cancers are sporadic or not inherited. Germline mutations in the breast and ovarian cancer susceptibility genes BRCA1 (MIM 113705) ${ }^{3}$ and BRCA2 (MIM 600185) ${ }^{45}$ confer a high risk of developing breast and ovarian cancers. Women with a mutation in the BRCA1 gene have a lifetime risk of $80-90 \%$ of developing breast cancer, and 40 $65 \%$ chance of developing ovarian cancer. ${ }^{6}$ For $B R C A 2$ gene mutation carriers, the estimated cumulative risk of breast cancer has been shown to be $28 \%$ by age 50 years, and $84 \%$ by age 70 years. ${ }^{7}$ The risk of ovarian cancer has been shown to be $0.4 \%$ by age 50 years and $27 \%$ by age 70 years. $^{7}$ Nevertheless, the magnitude of risk to carriers of the germline BRCA1 and BRCA2 remains controversial $^{2}$ and the controversy could partly have stemmed from the use of different populations and study designs, and the lack of specific mutation stratification. ${ }^{8}$

The Breast Cancer Information Core Database (BIC) lists more than 1560 and 1880 mutations and polymorphisms in the BRCA1 and BRCA2 genes respectively. The influences of each mutation type (genotype) on expressivity, cancer type and agedependent penetrance (phenotype) remain either controversial or unexplored. In the last decade, several reports have been published supporting the hypothesis that different mutations in the BRCA1 or BRCA2 genes confer different cancer-related risks. For example, Gayther et al (1995) reported that the risk of ovarian cancer relative to the risk of breast cancer was higher in families with mutations located $5^{\prime}$ to exon 13 of the BRCA1 gene compared with families with mutations located $3^{\prime}$ to exon 13." However, this finding was not confirmed in later reports. ${ }^{10-12}$ Also, an ovarian cancer cluster region (OCCR) in the BRCA2 gene was described by Gayther et al (1997). ${ }^{13}$ A later international collaborative study provided no statistically significant support for the existence of such a region, ${ }^{14}$ rather it was suggested that a reduced absolute risk of breast cancer for OCCR mutations contributed substantially to the effect described. ${ }^{15}$ All the above data pooled different but neighbouring BRCA1 or BRCA2 mutations and associated them with phenotypes. However, does a specific mutation in the BRCA1 or BRCA2 gene confer different phenotypes compared with other common mutations in the same gene? This is a question that remains unanswered especially pertaining to the recurrent BRCA1 exon 2, 11 and 13 mutations. The answer to this question could have important implications for screening, genetic counselling and prophylactic treatment of carriers. Therefore, there is currently a need to study the genotype-phenotype correlation among common mutations in BRCA1 and BRCA2 genes. Our paper addresses this need.

\section{METHODS}

\section{Patients}

A total of 241 patients and their family members from Yorkshire and Humberside, UK, were chosen for BRCA1 and BRCA2 mutation testing. They belonged to 131 families classified as moderate to high risk of carrying a $B R C A 1$ or $B R C A 2$ mutation. High-risk individuals were members of families with four confirmed cases of breast and/or ovarian cancers, with breast cancer occurring under the age of 60 years or ovarian cancer at any age. 
Moderate-risk groups were defined as families with three cases of cancer. Patients were followed up for a mean of 81.87 months (range 0.33-343.6 months), and age at diagnosis and overall survival were recorded. Mutational and corresponding clinical data were available for 219 cases. For calculating age at diagnosis, the age and date at which cancer of the breast or ovary occurred was noted. For calculating overall survival, the date of death was recorded. In addition, for other subjects with a follow-up date, but no date of death, this was coded as censored. For one subject with no follow-up time recorded but dates of diagnosis and follow-up, the follow-up time was calculated from the dates.

All patients and family members were counselled and signed a written informed consent before testing. The procedures followed were in accordance with the ethical standards implemented at the University of Kuwait and with the Declaration of Helsinki 1975, as revised in 1983.

Table 1 Breakdown of families with the most frequent BRCA1 mutations

\begin{tabular}{|c|c|c|c|c|c|}
\hline Family & Mutation & $\begin{array}{l}\text { Gene/ } \\
\text { exon }\end{array}$ & $\begin{array}{l}\text { No of } \\
\text { individuals }\end{array}$ & $\begin{array}{l}\text { No of } \\
\text { mutation } \\
\text { carriers }\end{array}$ & $\begin{array}{l}\text { No } \\
\text { affected }\end{array}$ \\
\hline 761 & 185delAG & BRCA1/2 & 4 & 1 & 0 \\
\hline 2802 & 185delAG & BRCA1/2 & 26 & 11 & 3 \\
\hline 5358 & 185delAG & BRCA1/2 & 2 & 1 & 1 \\
\hline 9603 & 185delAG & BRCA1/2 & 1 & 1 & 0 \\
\hline 9877 & 185delAG & BRCA1/2 & 4 & 4 & 1 \\
\hline 12654 & 185delAG & BRCA1/2 & 1 & 1 & 1 \\
\hline 13376 & 185delAG & BRCA1/2 & 2 & 1 & 1 \\
\hline 17240 & 185delAG & BRCA1/2 & 2 & 2 & 2 \\
\hline 17924 & 185delAG & BRCA1/2 & 2 & 1 & 1 \\
\hline 21347 & $185 \mathrm{del} A \mathrm{G}$ & BRCA1/2 & 2 & 2 & 2 \\
\hline 27388 & $185 \mathrm{del} A \mathrm{G}$ & BRCA1/2 & 4 & 2 & 1 \\
\hline 30231 & 185 delAG & BRCA1/2 & 2 & 1 & 1 \\
\hline 2592 & 4184delTCAA & BRCA1/11 & 3 & 2 & 1 \\
\hline 7836 & 4184delTCAA & BRCA1/11 & 4 & 3 & 1 \\
\hline 9117 & 4184delTCAA & BRCA1/11 & 4 & 2 & 1 \\
\hline 9430 & 4184delTCAA & BRCA1/11 & 3 & 2 & 2 \\
\hline 10079 & 4184delTCAA & BRCA1/11 & 3 & 2 & 1 \\
\hline 10502 & 4184delTCAA & BRCA1/11 & 2 & 1 & 1 \\
\hline 11096 & 4184delTCAA & BRCA1/11 & 3 & 1 & 1 \\
\hline 12779 & 4184delTCAA & BRCA1/11 & 3 & 1 & 1 \\
\hline 14028 & 4184delTCAA & BRCA1/11 & 2 & 2 & 2 \\
\hline 14562 & 4184delTCAA & BRCA1/11 & 3 & 2 & 1 \\
\hline 16324 & 4184delTCAA & BRCA1/11 & 1 & 1 & 1 \\
\hline 29694 & 4184delTCAA & BRCA1/11 & 7 & 4 & 3 \\
\hline 32778 & 4184delTCAA & BRCA1/11 & 1 & 1 & 1 \\
\hline 33164 & 4184deITCAA & BRCA1/11 & 1 & 1 & 1 \\
\hline 39265 & 4184delTCAA & BRCA1/11 & 3 & 3 & 3 \\
\hline 40426 & 4184deITCAA & BRCA1/11 & 1 & 1 & 0 \\
\hline 3140 & Exon13 Dup & BRCA1/13 & 3 & 2 & 1 \\
\hline 3429 & Exon13 Dup & BRCA1/13 & 2 & 2 & 1 \\
\hline 9592 & Exon13 Dup & BRCA1/13 & 3 & 1 & 1 \\
\hline 12157 & Exon13 Dup & BRCA1/13 & 1 & 1 & Unknown \\
\hline 12468 & Exon13 Dup & BRCA1/13 & 2 & 2 & 1 \\
\hline 20332 & Exon13 Dup & BRCA1/13 & 2 & 1 & 1 \\
\hline 20597 & Exon13 Dup & BRCA1/13 & 1 & 1 & 1 \\
\hline 21231 & Exon13 Dup & BRCA1/13 & 2 & 1 & 1 \\
\hline 25940 & Exon13 Dup & BRCA1/13 & 2 & 2 & 1 \\
\hline 27810 & Exon13 Dup & BRCA1/13 & 2 & 1 & 1 \\
\hline 32563 & Exon13 Dup & BRCA1/13 & 2 & 2 & 2 \\
\hline 36387 & Exon13 Dup & BRCA1/13 & 1 & 1 & 1 \\
\hline 38199 & Exon13 Dup & BRCA1/13 & 2 & 1 & 1 \\
\hline
\end{tabular}

\section{Mutation testing}

High-quality DNA was extracted from $5 \mathrm{ml}$ EDTA-treated venous blood samples using a standard phenol-chloroform procedure. All DNA samples were screened for mutations at exon 2 (185delAG), exon 20 (5382insC) of BRCA1, and exon 11 (6147delT) of $B R C A 2$, using amplification refractory mutation system PCR and duplication (Exon13dup6kb) of exon 13 by multiplex ligation-dependent probe amplification (P002; MRCHolland, Amsterdam, The Netherlands) as instructed by the kit manufacturer (level 1 testing). DNA negative for these mutations was subjected to level 2 testing, which involved direct sequencing of all exon 11 in eight large PCR fragments. Negative samples were then subjected to level 3 testing that called for single-strand conformation polymorphism (SSCP) analysis and sequencing of all BRCA1 coding exons. Therefore, all samples that were negative for levels 1, 2 and SSCP were sequenced. In all reactions, positive (DNA with known mutations) and negative controls (wild-type DNA from normal individuals) were included. Primer sequences and reaction conditions are available online. ${ }^{16}$

\section{Statistical analysis}

Two outcomes were considered: age at diagnosis and time from diagnosis to death. As both of these are time to event data, Cox proportional hazards regression was used. Four groups of subjects were compared, defined by the exon where the mutation took place: exon 2, exon 11, exon 13 and all other exons. The hazard ratio for each group, exon 2, 11 and 13, compared to the other exons group were calculated, with an overall significance test of the effect of exon and confidence intervals for each hazard ratio. Patients were grouped into pedigrees, where more than one patient may belong to the same pedigree. Clustering within pedigrees was be adjusted for using robust standard errors by the method of Lin and Wei. ${ }^{17}$ For the time to death, we also controlled for age at diagnosis, to allow for potentially greater mortality among older women. All analyses were done using Stata 8 (Stata, College Station, Texas, USA).

\section{RESULTS}

\section{BRCA1 and BRCA2 mutation frequencies in Yorkshire}

The present study included 131 families with moderate to high risk of carrying BRCA1 or BRCA2 mutations (table 1). An example pedigree from a family with exon 13 duplication is shown in supplementary fig 1. A total of 241 patients and their family members were screened for pathogenic germline mutations in the BRCA1 or BRCA2 gene.

One hundred and thirty-six (56\%) individuals carried a mutated BRCA1 gene, 25 (10\%) had a mutated BRCA2 gene, and $80(33 \%)$ of the screened individuals carried wild-type genes. Tables 2 and 3 give the frequency and type of mutations in various exons of $B R C A 1$ and $B R C A 2$ genes respectively. The vast majority of mutations caused protein truncation. Moreover, we identified 14 novel mutations not previously reported in the BIC database. ${ }^{18}$

For the BRCA1 gene, mutations in exon 11 were the most frequent ( $\mathrm{n}=58$, or $42.3 \%$ ) with 4184 delTCAA accounting for the most common mutation within exon $11(n=29$, or $50 \%$ ). Exon 2 mutations were the second most frequent $(n=30$, or $22 \%$ ) with 185delAG being the most common mutation within exon $2(\mathrm{n}=28$, or $93.3 \%)$ followed by mutation of exon 13 $(\mathrm{n}=20$, or $14.6 \%)$ and exon $20(\mathrm{n}=12$, or $8.7 \%)$. For $B R C A 2$ 
Table 2. Frequencies and types of $B R C A 1$ familial mutations

\begin{tabular}{|c|c|c|}
\hline Exon no & $\begin{array}{l}\text { Familial } \\
\text { mutation }\end{array}$ & $\begin{array}{l}\text { No of individuals (\%) with } \\
\text { BRCA1 mutations }(\mathrm{n}=136)\end{array}$ \\
\hline \multirow[t]{21}{*}{11} & 917_918delTT & $1(1.7)$ \\
\hline & 887insAG* & $1(1.7)$ \\
\hline & 887insA* & $1(1.7)$ \\
\hline & 4184delTCAA & $29(49.2) \neq$ \\
\hline & 3896delT & $5(8.5)$ \\
\hline & 3889delAG & $3(5.1)$ \\
\hline & 3875delGTCT & $2(3.4)$ \\
\hline & $3519 G>T$ (E1134X) & $1(1.7)$ \\
\hline & 3450_3453delCAAG & $1(1.7)$ \\
\hline & $2871 \mathrm{~A}>\mathrm{C}^{*}$ & $1(1.7)$ \\
\hline & 2800delAA & $1(1.7)$ \\
\hline & $2682 C>T(0855 X)$ & $1(1.7)$ \\
\hline & 2594delC & $2(3.4)$ \\
\hline & 2559 ins $A^{*}$ & $1(1.7)$ \\
\hline & $2196 \mathrm{G}>\mathrm{A}(\mathrm{D} 693 \mathrm{~N})$ & $1(1.7)$ \\
\hline & 2080delA & $1(1.7)$ \\
\hline & 2011 ins $T$ & $1(1.7)$ \\
\hline & $1927 C>G^{*}$ & $1(1.7)$ \\
\hline & 1623del5bp & $2(3.4)$ \\
\hline & 1294del40bp & $2(3.4)$ \\
\hline & Total & 58 \\
\hline \multirow[t]{4}{*}{13} & Ex13ins6kb & $4(20)$ \\
\hline & ex13 dup & $14(70) \S$ \\
\hline & $4446 \mathrm{C}>\mathrm{T}(\mathrm{R} 1443 \mathrm{X})$ & $2(10)$ \\
\hline & Total & 20 \\
\hline \multirow[t]{3}{*}{15} & 4693delAA & $1(50)$ \\
\hline & $4654 G>T(S 1512 I)$ & $1(50)$ \\
\hline & Total & 2 \\
\hline \multirow[t]{2}{*}{16} & 5075G >A (M1652I) & $1(100)$ \\
\hline & Total & 1 \\
\hline \multirow[t]{2}{*}{$1 \mathrm{~A}-2$} & Exons $1 \mathrm{~A}-2$ deletion & $2(100)$ \\
\hline & Total & 2 \\
\hline \multirow[t]{4}{*}{2} & 187-188delAG* & $1(3.3)$ \\
\hline & $185 i n s A \dagger$ & $1(3.3)$ \\
\hline & 185delAG & $28(93.3)$ \\
\hline & Total & 30 \\
\hline \multirow[t]{4}{*}{20} & ivs20+60 ins12bp & $1(8.3)$ \\
\hline & Exon 20 deletion & $7(58.3)$ \\
\hline & 5382insC & $4(33.3)$ \\
\hline & Total & 12 \\
\hline \multirow[t]{2}{*}{22} & $5452-2 A>C^{*}$ & $1(100)$ \\
\hline & Total & 1 \\
\hline \multirow[t]{2}{*}{24} & $5622 \mathrm{C}>\mathrm{T}(\mathrm{R} 1835 \mathrm{X})$ & $5(100)$ \\
\hline & Total & 5 \\
\hline \multirow[t]{2}{*}{3} & Exon 3 deletion & $3(100)$ \\
\hline & Total & 3 \\
\hline \multirow[t]{2}{*}{5} & $300 \mathrm{~T}>\mathrm{C}(\mathrm{C} 61 \mathrm{R})$ & $1(100)$ \\
\hline & Total & 1 \\
\hline \multirow[t]{2}{*}{7} & 421-2delA & $1(100)$ \\
\hline & Total & 1 \\
\hline
\end{tabular}

*Novel mutations not reported in the Breast Cancer Information Core database. tReported in Pakistan. ${ }^{36}$

:Number of families $=13$

$\S$ Number of families $=12$

- Number of families $=11$.

gene, mutations in exon 11 were the most frequent $(n=18$, or $75 \%)$.

Association of BRCA1 and BRCA2 gene mutations with cancer occurrence and site

Matched mutations and clinical data were available for 219 individuals. The cohort included $40(18 \%)$ males and $179(82 \%)$
Table 3. Frequencies and types of BRCA2 familial mutations

\begin{tabular}{|c|c|c|}
\hline Exon no & $\begin{array}{l}\text { Familial } \\
\text { mutation }\end{array}$ & $\begin{array}{l}\text { No of individuals }(\%) \text { with } \\
\text { BRCA2* mutations }(n=25)\end{array}$ \\
\hline \multirow[t]{13}{*}{11} & 6714_6717delACAA & $2(11.8)$ \\
\hline & 6503delTT & $1(5.9)$ \\
\hline & 6174delT & $1(5.9)$ \\
\hline & $6137 C>A(S 1970 X)$ & $2(11.8)$ \\
\hline & 5950delCT & $2(11.8)$ \\
\hline & 5368delATTT** & $1(5.9)$ \\
\hline & 5056insG* & $3(17.6)$ \\
\hline & 4859insA & $2(11.8)$ \\
\hline & 4329ins $A^{*}$ & $1(5.9)$ \\
\hline & 4329 delA* & $1(5.9)$ \\
\hline & 3386T > G (L1053X) & $1(5.9)$ \\
\hline & 3036delACAA & $1(5.9)$ \\
\hline & Total & 18 \\
\hline \multirow[t]{2}{*}{2} & $295 G>T$ & $4(100)$ \\
\hline & Total & 4 \\
\hline \multirow[t]{2}{*}{23} & 9138insA* & 1 \\
\hline & Total & 1 \\
\hline \multirow[t]{2}{*}{8} & $860-1 G>A^{*}$ & $2(100)$ \\
\hline & Total & 2 \\
\hline
\end{tabular}

females. As expected, there was a significant association between the presence of BRCA1 or BRCA2 mutations and the occurrence of cancer; $\mathrm{p}<0.0001$ (table 4). Of the affected cases, 63 had invasive breast cancer, 12 were diagnosed with ovarian cancer, 15 had both breast and ovarian cancers, one man
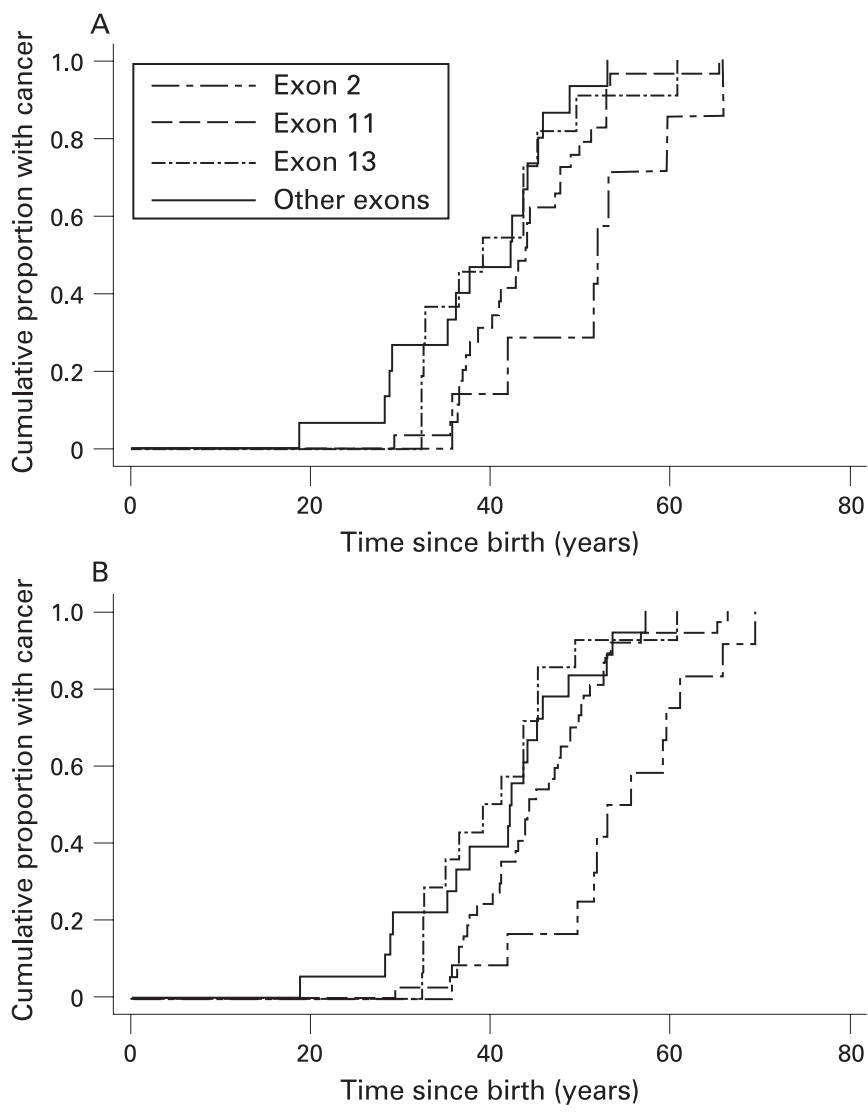

Figure 1 (A) Cumulative incidence for all cancer cases, by various BRCA1 exons. (B) Cumulative incidence of breast cancer cases, by various $B R C A 1$ exons. 
Table 4 Clinical characteristics of patients in relation to BRCA1 and BRCA2 mutations

\begin{tabular}{|c|c|c|c|c|}
\hline Clinical data & $\begin{array}{l}\text { Number } \\
\text { of } \\
\text { patients } \\
\text { or age }\end{array}$ & $\begin{array}{l}\text { Mutations in } \\
\text { BRCA1 and } \\
\text { BRCA2 } \\
\text { genes }\end{array}$ & $\begin{array}{l}\text { Wild-type } \\
\text { BRCA1 and } \\
\text { BRCA2 } \\
\text { genes }\end{array}$ & $\begin{array}{l}\text { p } \\
\text { Value* }\end{array}$ \\
\hline \multicolumn{5}{|l|}{ Phenotype } \\
\hline No with cancer & 102 & 98 & 4 & 0.0001 \\
\hline No cancer free & 117 & 44 & 73 & \\
\hline Mean age (years) & 47.7 & & & \\
\hline $\begin{array}{l}\text { Mean age of patients with } \\
\text { cancer }\end{array}$ & 46 & 45.8 & 49.2 & $0.006 \dagger$ \\
\hline $\begin{array}{l}\text { Mean age of cancer-free } \\
\text { individuals }\end{array}$ & 49.2 & 46.7 & 50.8 & \\
\hline
\end{tabular}

*Calculated using two-sided Fisher's exact test.

$\uparrow$ Student $t$ test was used to compare means.

developed colon and prostate cancers, one woman presented with ovarian and vaginal cancers, and another woman presented with breast and pancreatic adenocarcinomas. Table 5 lists cancer sites in relation to BRCA1 and BRCA2 mutations. Mutations in the BRCA1 gene accounted for the majority of breast and ovarian cancers in these families. In addition, BRCA1 mutations accounted for the majority of patients with both breast and ovarian cancers. BRCA2 mutations were more common in breast than ovarian cancer (the ratio of breast to ovarian cancers was 9:1). This is consistent with data from the Breast Cancer Linkage Consortium. ${ }^{7}$ Although the numbers were modest, mutations in the BRCA2 gene were significantly associated with the development of cancers outside the breastovarian axis (table 5).

There was evidence that mutations in the $3^{\prime}$ end of the BRCA1 gene ( $3^{\prime}$ to exon 13) were less likely to be associated with ovarian cancer. For example, $90 \%$ of ovarian cancers were associated with mutations in the $5^{\prime}$ end of the BRCA1 gene, while only $10 \%$ were linked to mutations in the $3^{\prime}$ end. However, this trend was not statistically significant.

\section{BRCA1 exon 2 mutation penetrance}

We noted that carriers of the exon 2 BRCA1 gene mutation had significantly lower cancer incidence compared with carriers of mutations of exons 11, 13 and 20. In this regard, table 6 shows that $15(56 \%)$ of patients who carried the BRCA1 185delAG mutation were cancer free $(p=0.004)$. This suggested to us that either the 185delAG mutation is of low penetrance or, more likely, carriers of this mutation would develop cancer at an older age compared with other BRCA1 gene mutations. This observation led us to explore age-dependant expressivity of various BRCA1 exon mutations.

\section{BRCA1 mutations and age-related expressivity}

Of the 136 cases carrying a mutated BRCA1 gene, 79 women who developed breast and/or ovarian cancers were included in the analysis (table 7). Analysis of age-related expressivity pertaining to various $B R C A 2$ gene mutations was not performed because of the small number of cases included in each mutation category. For BRCA1 gene, groups of patients were compared, defined by the exon where the mutations were located: exon 2 , exon 11, exon 13, and all other exons. Patients were grouped into pedigrees, where more than one patient may belong to the same pedigree. Cox regression with clustering on pedigree showed that the exon was a highly significant predictor $\left(\chi^{2}\right.$ 19.75 with 3 degrees of freedom, $p=0.0002)$. Hence, there was a significant relationship between a specific exon mutation and
Table 5 Cancer sites in relation to BRCA1 and BRCA2 mutations

\begin{tabular}{lcccc}
\hline & $\begin{array}{l}\text { Mutation } \\
\text { in } \\
\text { Cancer site* }\end{array}$ & $\begin{array}{l}\text { Mutation in } \\
\text { BRCA2 }\end{array}$ & Total & p Value $\dagger$ \\
\hline Breast & 54 & 9 & 63 & 0.001 \\
Ovary & 12 & 0 & 12 & \\
Breast and ovary & 13 & 2 & 15 & \\
Breast or ovary and other & 0 & 2 & 2 & \\
sites & 0 & 1 & 1 & \\
Other sites & 79 & 14 & 93 & \\
Total & & & & \\
\hline
\end{tabular}

* Site was unknown for five of 98 patients with cancer (three with exon 11, and two other exon mutations in the BRCA1 gene).

$\uparrow$ Calculated using two-sided Fisher's exact test.

age at diagnosis, mainly due to exon 2 having a much lower hazard or older age at diagnosis than the other groups (table 7). Clustering within pedigrees may have an adverse effect on $p$ values and standard errors. The cumulative incidence for all cancer cases, or limited to breast cancers, and stratified by various BRCA1 exon mutations is shown in fig 1 .

We then asked if the relationship between various BRCA1 exon mutations and age at diagnosis is different for different cancer sites. For this, we carried out Cox regression analysis with exon and tumour site as factors. The estimates of the hazard ratios were very little changed by including both exon and tumour site $\left(\chi^{2}\right.$ statistic 23.09 with 5 degrees of freedom, $\mathrm{p}=0.0003$ ) (table 8). Also, limiting the analysis to woman with breast cancer only, the hazard ratios changed very little (table 9). This is not surprising, as most of the women belonged to this group. Hence there is strong evidence that various BRCA1 exon mutations have an effect on age-dependent expressivity that was not explained by cancer site.

\section{Specific BRCA1 mutations and age-related expressivity}

Exon 11 is the largest exon in the BRCA1 gene and harbours a number of different mutations in different patients; these mutations were grouped in this study under the term "exon 11 mutations". To minimise any confounding error emanating from such grouping, we limited the analysis to three specific and most common mutations in exons 2, 11 and 13, namely, 185delAG, 4184delTCAA and exon 13 duplication, respectively (table 1). Figure 2 shows that median age of affliction with breast cancer was 55 years for 185delAG in exon 2 (hazard ratio (HR) $0.23,95 \%$ CI 0.095 to $0.55, p=0.001)$ and 47 years for the 4184delTCAA mutation in exon 11 (HR 0.49 , 95\% CI 0.225 to $1.08, \mathrm{p}=0.076$ ) compared with 41 years for exon 13 duplication of the BRCA1 gene. It is worthy of note that the inclusion of a large pedigree (2802) carrying the 185delAG mutation could have confounding influence on the major conclusion emanating from our study. However, exclusion of this pedigree from the analysis did not have any impact on our data stating that exon 2

Table 6 Relationship between various mutated BRCA1 exons and affliction with cancer

\begin{tabular}{clll}
\hline Mutated exon no. & $\begin{array}{l}\text { Affected with cancer, } \\
\mathbf{n = 8 4}(\%)\end{array}$ & $\begin{array}{l}\text { Cancer free, } \\
\mathbf{n = 3 7}(\%)\end{array}$ & Total, $\mathbf{n = 1 2 1}$ \\
\hline 11 & $38(71.7)$ & $15(28.3)$ & 53 \\
13 & $13(72.2)$ & $5(27.8)$ & 18 \\
2 & $12(44.4)$ & $15(55.6)^{*}$ & 27 \\
Other exons & $21(91)$ & $2(9)$ & 23
\end{tabular}

${ }^{*} p=0.004$ using two-sided Fisher's exact test. 
Table 7 Cox regression analysis between specific BRCA1 exon mutation and age at diagnosis

\begin{tabular}{lllc}
\hline Mutation & Hazard ratio & Standard error & $\mathbf{p}$ Value $(95 \% \mathrm{Cl})$ \\
\hline Exon 11 & 0.69 & 0.21 & $0.2(0.38$ to 1.25$)$ \\
Exon 2 & 0.28 & 0.09 & $<0.001(0.15$ to 0.54$)$ \\
Exon 13 & 1.16 & 0.51 & $0.7(0.49$ to 2.75$)$
\end{tabular}

Hazard ratio of $<1$ indicates lower hazard than the other groups and hence older ages at diagnosis.

mutation 185delAG has lower penetrance that is age dependent (HR $0.22,95 \%$ CI 0.09 to $0.56, p=0.002$ ).

\section{BRCA1 mutations and survival analysis}

Overall survival data were available from 61 patients. The Cox regression with clustering on pedigree, including BRCA1 exon mutation and age at diagnosis, gave no overall significant prediction: $\chi^{2}=3.72$ with 4 degrees of freedom, $p=0.4$. Thus there was no evidence that any specific BRCA1 exon mutation can predict overall survival from date of diagnosis. However, as expected, risk of death increased slightly with age at diagnosis, though this was not significant. The raised HRs suggest that this analysis would be worth repeating with a much larger sample (fig 3).

\section{DISCUSSION}

The aim of this study was to elaborate on the expressivity of various $B R C A 1$ gene mutations in relation to penetrance and age of cancer diagnosis. To this end, a total of 241 patients and their family members (of whom 219 had relevant clinical data) were screened for pathogenic germline mutations in BRCA1 or BRCA2 genes and the results were associated with clinical parameters. We opted for a family-based study to maximise the number of individuals with mutated BRCA1 or BRCA2 genes. Although this approach suffers from bias compared with a populationbased study, it was necessary as the latter approach requires a very large cohort to attain a similar number of individuals with mutated BRCA1 or BRCA2 genes. Therefore, $>4000$ individuals in a population are required to be tested to yield 141 individuals with BRCA1 or BRCA2 mutations. ${ }^{19}$ The extent of bias is difficult to infer. For example, it is generally accepted that family-based studies usually overestimate the lifetime risks of cancer because the presence of additional genetic factors could elevate risks for the relatives. Nevertheless, the use of appropriate statistical methods could alleviate some aspects of this bias. $^{20} 21$

In this study we have exhaustively searched for mutations in the BRCA1 and BRCA2 genes using a level approach that involved starting from screening for known founder mutations up to sequencing all exons in addition to various exon rearrangements. This methodology would increase the sensitivity of detecting BRCA1 and BRCA2 gene mutations, and this was reflected in our high pickup mutation rate accounting for $67 \%$ of individuals recruited in this study. A total of $56 \%$ of individuals harboured a BRCA1 mutated gene; this figure is similar to the one previously estimated for the UK population. ${ }^{9}$ Similarly, the proportion of BRCA2 mutation-bearing individuals in this study is within the range previously published for the UK. ${ }^{22}$ It is well accepted that mutation frequencies of the $B R C A 1$ and BRCA2 genes in high-risk families vary widely among different populations, being highest in Russia for $B R C A 1^{23}$ and in Iceland for BRCA2. ${ }^{24}$ This could be due to ascertainment or methodological bias, or more likely it is a reflection of human migration and establishment of founders.
Table 8 Cox regression analysis including specific BRCA1 exon mutation and cancer sites as covariates

\begin{tabular}{llc}
\hline Mutation & Hazard ratio & $\mathbf{p}$ Value $(\mathbf{9 5} \% \mathrm{Cl})$ \\
\hline Exon 11 & 0.64 & $0.1(0.37$ to 1.11$)$ \\
Exon 2 & 0.29 & $<0.001(0.15$ to 0.53$)$ \\
Exon 13 & 0.98 & $0.97(0.40$ to 2.42$)$ \\
Ovary & 0.46 & $0.009(0.26$ to 0.82$)$ \\
Other exons & 0.76 & $0.3(0.47$ to 1.24$)$ \\
\hline
\end{tabular}

In our UK East Midlands series, three mutations in the BRCA1 gene were recurrent, namely 4184delTCAA, accounting for the most common mutation within exon 11 (found in 16 families), 185delAG, being the most frequent mutation within exon 2 (found in 11 families), and duplication of exon 13 (found in 12 families). The BIC database lists 185delAG, 4184delTCAA and exon 13 duplication among the 20 most frequent recurrent mutations ${ }^{18}$; these are consistent with our data. Also, our data are in line with the fact that BRCA1 exon 13 duplication has been reported as a founder mutation in Britain, and Englishspeaking counties with historical links to Britain. In that regard, $50 \%$ of the exon 13 duplication mutations were demonstrated in Britain, mainly Yorkshire, suggesting a northern British origin for this mutation (the BRCA1 exon 13 screening group). ${ }^{25}$ Interestingly, none of the $B R C A 2$ mutations were repeated in more than two families, probably indicating the presence of many BRCA2 founders (or de novo mutations). Although we did not haplotype families carrying the 185delAG mutation, previous haplotypes from Yorkshire indicated independent origins of the mutation from the Jewish founders. ${ }^{26}$

Our data are consistent with the fact that mutations in $B R C A 1$ and $B R C A 2$ are associated with increased risk of cancer. ${ }^{327}$ Both BRCA1 and BRCA2 mutations were significantly associated with development of breast cancer. On the other hand, BRCA2, but not the BRCA1 gene, was significantly linked to the development of cancer outside the breast-ovarian axis. This is in agreement with data showing that mutations in the $B R C A 1$ gene are rarely linked to cancer at sites other than breast and ovary, while mutations in the BRCA2 gene are. ${ }^{28} 29$

Regarding the controversial issue linking mutations of the $3^{\prime}$ end of the BRCA1 to lower incidence of ovarian cancer, our data show that ovarian cancer is indeed lower when mutations inflict the $3^{\prime}$ end of the BRCA1 gene. However, the trend was insignificant and a larger study is needed to resolve this issue. ${ }^{9}$

Perhaps the most intriguing finding of this study was the notion that different mutations in the BRCA1 gene have significantly different effect on age-dependent expressivity. To the best of our knowledge this is the first time that different age-dependent expressivity, independent of cancer site, has been reported for three of the most common BRCA1 mutations, namely 185delAG, 4184delTCAA and exon 13 duplication. For the exon 13 duplication mutation, we reported a mean age of cancer diagnosis at 41.4 years (95\% CI 36.99 to 45.78) from 12 independent families. Data on the age-dependent penetrance/ expressivity for exon 13 duplication are scarce. However, Unger

Table 9 Cox regression analysis between specific BRCA1 exon mutation and age at diagnosis limited to breast cancer only

\begin{tabular}{lll}
\hline Mutation & Hazard ratio & $\mathbf{p}$ Value $(95 \% \mathrm{CI})$ \\
\hline Exon 11 & 0.61 & $0.1(0.32$ to 1.13$)$ \\
Exon 2 & 0.26 & $0.002(0.11$ to 0.62$)$ \\
Exon 13 & 0.80 & $0.6(0.32$ to 2.03$)$ \\
\hline
\end{tabular}




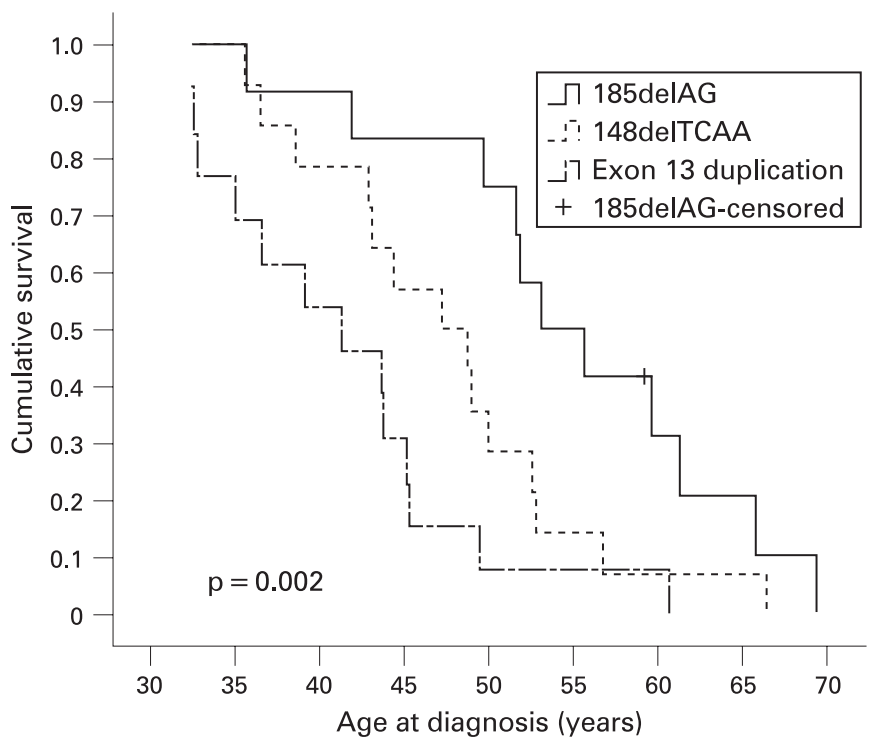

\begin{tabular}{|c|c|c|c|c|c|c|c|c|}
\hline \multirow{3}{*}{ Mutation } & \multicolumn{4}{|c|}{ Mean } & \multicolumn{4}{|c|}{ Median } \\
\hline & \multirow{2}{*}{ Estimate } & \multirow{2}{*}{$\begin{array}{c}\text { Standard } \\
\text { error }\end{array}$} & \multicolumn{2}{|c|}{$95 \% \mathrm{Cl}$} & \multirow{2}{*}{ Estimate } & \multirow{2}{*}{$\begin{array}{c}\text { Standard } \\
\text { error }\end{array}$} & \multicolumn{2}{|c|}{$95 \% \mathrm{Cl}$} \\
\hline & & & \begin{tabular}{|c|} 
Lower \\
boundary
\end{tabular} & $\begin{array}{c}\text { Upper } \\
\text { boundary }\end{array}$ & & & $\begin{array}{c}\text { Lower } \\
\text { boundary }\end{array}$ & $\begin{array}{c}\text { Upper } \\
\text { boundary }\end{array}$ \\
\hline \multirow{4}{*}{$\begin{array}{l}\text { 4184delTCAA } \\
\text { 185delAG } \\
\text { exon } 13 \\
\text { Duplication } \\
\text { Overall }\end{array}$} & 47.479 & 2.234 & 43.101 & 51.857 & 47.247 & 4.182 & 39.049 & 55.444 \\
\hline & 55.026 & 2.898 & 49.347 & 60.706 & 53.140 & 3.253 & 46.764 & 59.515 \\
\hline & 41.386 & 2.243 & 36.990 & 45.783 & 41.323 & 4.274 & 32.945 & 49.701 \\
\hline & 47.767 & 1.632 & 44.568 & 50.965 & 47.247 & 2.884 & 41.594 & 52.899 \\
\hline
\end{tabular}

Figure 2 Kaplan-Meier plots of cumulative survival and age at diagnosis with breast cancer in relation to specific BRCA1 exon mutations. The p value indicates log-rank test.

et al reported a Belgian woman with this mutation who developed cancer at age 34 years. ${ }^{30}$ Moreover, Yap et al reported a woman diagnosed with bilateral breast cancer at ages 32 and 41 years and her sister, carrying the same exon 13 duplication mutation, was diagnosed with ovarian cancer at age 43 years. ${ }^{31}$ For the 185delAG BRCA1 mutation, although the frequency of the mutation was, as expected, among the highest, we report

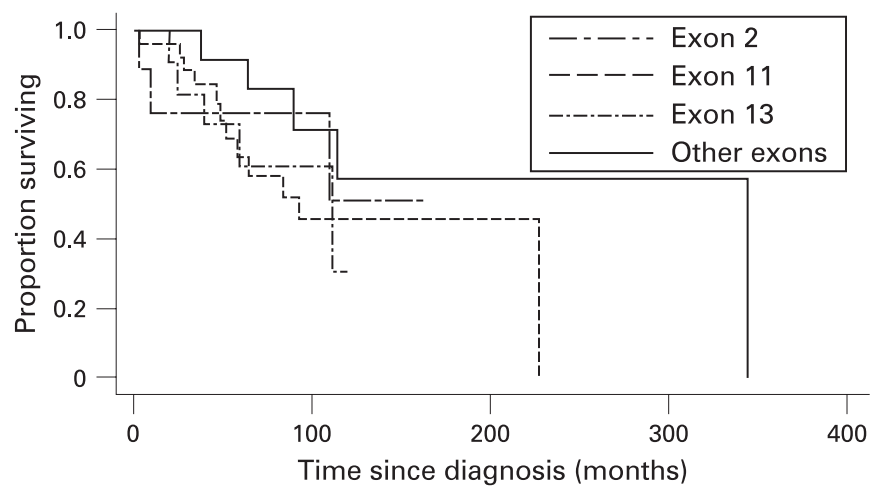

\begin{tabular}{|l|c|c|c|c|}
\hline Interval & Hazard ratio & $\begin{array}{c}\text { Standard } \\
\text { error }\end{array}$ & $\mathrm{p}$ Value & $95 \% \mathrm{Cl}$ \\
\hline Exon 11 & 2.15 & 1.11 & 0.1 & 0.78 to 5.90 \\
Exon 2 & 1.48 & 1.11 & 0.6 & 0.34 to 6.45 \\
Exon 13 & 2.52 & 1.52 & 0.1 & 0.77 to 8.23 \\
$\begin{array}{l}\text { Age at } \\
\text { diagnosis }\end{array}$ & 1.027 & 0.034 & 0.6 & 0.95 to 1.09 \\
\hline
\end{tabular}

Figure 3 Kaplan-Meier plot of overall survival of patients in relation to BRCA1 exon mutations (the table depicts the hazard ratios). significantly lower cancer rates in carriers of this mutation. This has been observed before in Iraqi/Iranian women, who have a significantly lower penetrance compared with Ashkenazi Jewish woman carrying the same mutation. ${ }^{32}$ Therefore, it remains to be elucidated whether this difference in penetrance could be due to other genetic variation such as different haplotypes, environmental or cultural influences. More importantly, we report here that the mean age of cancer diagnosis from 12 separate families carrying the $185 \mathrm{del} A \mathrm{G}$ mutation was 55 years (95\% CI 49.3 to 60.7), which is a significantly older age of cancer diagnosis compared with exon 13 duplication mutation. In a recent report, using a meta-analysis of pedigree data from 498 BRCA1 and BRCA2 mutation carriers identified through population-based studies of women with breast and ovarian cancer, the authors have shown, albeit not significantly, that cancer risk by age 50 years is lower for 185delAG than 5382insC BRCA1 mutation carriers. ${ }^{19}{ }^{33}$ Our data are consistent with this. The question of why the 185delAG mutation has a lower cancer-related expressivity that is age dependent compared to other BRCA1 mutations remains to be elucidated. Recently, however, Perrin-Vidoz et al, reported that transcripts bearing the 185delAG mutation are not subjected to degradation by nonsense-mediated mRNA decay. ${ }^{34}$ This important observation leads us to hypothesise that even in the presence of the 185delAG mutation there could still be some truncated, but functional, BRCA1 protein delaying the onset of cancer. In support of this, Buisson et al have demonstrated translational re-initiation in the BRCA1 minigenes at position 128 in the presence of a premature termination codon at position 36 or 39. ${ }^{35}$ However, using western blotting and immunoprecipitation, we and Buisson et al were unable to detect $\mathrm{N}$-terminally or 


\section{Take-home messages}

- The 185delAG mutation of the BRCA1 gene is a low penetrance mutation that is age dependent.

- Carriers of the exon 13 duplication mutation are at risk of developing cancer at younger age.

- We report 14 novel mutations in the BRCA1 and BRCA2 genes in the Yorkshire/Humberside population.

- Clinical geneticists should take the mutation site and type into consideration in risk calculations.

C-terminally truncated BRCA1 proteins from lymphocytes of carriers, probably indicating an unstable nature of the truncated BRCA1 protein. ${ }^{35}$ Nevertheless, the truncated BRCA1 protein could still be functional in a microenvironment or at concentrations beyond the detection limit of current technologies. This hypothesis remains to be proven. Obviously, the role of other genetic background or haplotypes and environmental influences on age-dependent expressivity cannot be underestimated. For example, we do not know whether carriers of exon 13 duplication in the BRCA1 gene have other genetic aberrations that could influence expressivity. Regardless of the mechanism, our findings have important ramifications regarding the design of future studies for the estimation of cancer risks and more specifically on the counselling of patients with BRCA1 mutations, in that the mutation type should be included in risk calculations. Moreover, the time of screening and prophylactic treatments of carriers should be adjusted to take into account the different age-dependent expressivity of various BRCA1 gene mutations.

Acknowledgements: We dedicate this work in memory of Elizabeth Redmond. We would like to thank the staff of DNA laboratory at St James's Hospital Leeds for their help and support with the data. Part of this work was supported by grant number (2006130207) given to Fahd Al-Mulla by the Kuwait Foundation for the Advancement of Sciences.

Competing interests: None.

\section{REFERENCES}

1. Parkin DM, Bray F, Ferlay J, et al. Global cancer statistics, 2002. CA Cancer J Clin 2005; $55: 74-108$.

2. Narod SA. Modifiers of risk of hereditary breast and ovarian cancer. Nat Rev Cancer 2002;2:113-23.

3. Miki Y, Swensen J, Shattuck-Eidens D, et al. A strong candidate for the breast and ovarian cancer susceptibility gene BRCA1. Science 1994;266:66-71.

4. Tavtigian SV, Simard J, Rommens J, et al. The complete BRCA2 gene and mutations in chromosome 13q-linked kindreds. Nat Genet 1996;12:333-7.

5. Wooster R, Neuhausen SL, Mangion J, et al. Localization of a breast cancer susceptibility gene, BRCA2, to chromosome 13q12-13. Science 1994;265:2088-90.

6. Ford D, Easton DF, Bishop DT, et al. Risks of cancer in BRCA1-mutation carriers. Breast Cancer Linkage Consortium. Lancet 1994;343:692-5.

7. Ford D, Easton DF, Stratton M, et al. Genetic heterogeneity and penetrance analysis of the BRCA1 and BRCA2 genes in breast cancer families. The Breast Cancer Linkage Consortium. Am J Hum Genet 1998;62:676-89.

8. Begg CB. On the use of familial aggregation in population-based case probands for calculating penetrance. J Natl Cancer Inst 2002;94:1221-6.

9. Gayther SA, Warren W, Mazoyer S, et al. Germline mutations of the BRCA1 gene in breast and ovarian cancer families provide evidence for a genotype-phenotype correlation. Nat Genet 1995;11:428-33.
10. Couch FJ, DeShano ML, Blackwood MA, et al. BRCA1 mutations in women attending clinics that evaluate the risk of breast cancer. N Engl J Med 1997;336:1409-15.

11. Frank TS, Manley SA, Olopade Ol, et al. Sequence analysis of BRCA1 and BRCA2 correlation of mutations with family history and ovarian cancer risk. J Clin Oncol 1998; 16:2417-25.

12. Serova 0, Montagna $\mathrm{M}$, Torchard $\mathrm{D}$, et al. A high incidence of BRCA1 mutations in 20 breast-ovarian cancer families. Am J Hum Genet 1996;58:42-51.

13. Gayther SA, Mangion J, Russell $P$, et al. Variation of risks of breast and ovarian cancer associated with different germline mutations of the BRCA2 gene. Nat Genet 1997:15:103-5

14. Neuhausen SL, Godwin AK, Gershoni-Baruch R, et al. Haplotype and phenotype analysis of nine recurrent BRCA2 mutations in 111 families: results of an international study. Am J Hum Genet 1998;62:1381-8.

15. Thompson D, Easton D. Variation in cancer risks, by mutation position, in BRCA2 mutation carriers. Am J Hum Genet 2001;68:410-9.

16. Al-Mulla F. http://www.al-mulla.org/breastcancer.html laccessed 15 December 2008).

17. Lin DY, Wei LJ. The robust inference for the Cox proportional hazards model. J Am Stat Assoc 1989;84:1074-8.

18. National Human Genome Research Institute. Breast Cancer Information Core database. http://research.nhgri.nih.gov/bic/ (accessed 15 December 2008).

19. Antoniou A, Pharoah PD, Narod S, et al. Average risks of breast and ovarian cancer associated with BRCA1 or BRCA2 mutations detected in case series unselected for family history: a combined analysis of 22 studies. Am J Hum Genet 2003;72:1117-30.

20. Chatterjee N, Wacholder S. A marginal likelihood approach for estimating penetrance from kin-cohort designs. Biometrics 2001;57:245-52.

21. Kraft $\mathbf{P}$, Thomas DC. Bias and efficiency in family-based gene-characterization studies: conditional, prospective, retrospective, and joint likelihoods. Am J Hum Genet 2000;66:1119-31.

22. Szabo $\mathbf{C l}$, King MC. Population genetics of BRCA1 and BRCA2. Am J Hum Genet 1997;60:1013-20.

23. Gayther $\mathbf{S A}$, Harrington $\mathrm{P}$, Russell $\mathrm{P}$, et al. Frequently occurring germ-line mutations of the BRCA1 gene in ovarian cancer families from Russia. Am J Hum Genet 1997;60:1239-42.

24. Thorlacius S, Olafsdottir G, Tryggvadottir $\mathrm{L}$, et al. A single BRCA2 mutation in male and female breast cancer families from Iceland with varied cancer phenotypes. Nat Genet 1996:13:117-9.

25. The BRCA1 Exon 13 Duplication Screening Group. The exon 13 duplication in the BRCA1 gene is a founder mutation present in geographically diverse populations. Am J Hum Genet 2000;67:207-12.

26. Xu CF, Chambers JA, Nicolai $\mathrm{H}$, et al. Mutations and alternative splicing of the BRCA1 gene in UK breast/ovarian cancer families. Genes Chromosomes Cancer 1997:18:102-10.

27. Hall JM, Lee MK, Newman B, et al. Linkage of early-onset familial breast cancer to chromosome 17q21. Science 1990;250:1684-9.

28. Phelan CM, Lancaster JM, Tonin $\mathrm{P}$, et al. Mutation analysis of the BRCA2 gene in 49 site-specific breast cancer families. Nat Genet 1996;13:120-2.

29. Thompson D, Easton DF. Cancer incidence in BRCA1 mutation carriers. J Natl Cancer Inst 2002;94:1358-65.

30. Unger MA, Nathanson KL, Calzone $K$, et al. Screening for genomic rearrangements in families with breast and ovarian cancer identifies BRCA1 mutations previously missed by conformation-sensitive gel electrophoresis or sequencing. Am J Hum Genet 2000;67:841-50.

31. Yap KP, Ang P, Lim IH, et al. Detection of a novel Alu-mediated BRCA1 exon 13 duplication in Chinese breast cancer patients and implications for genetic testing. Clin Genet 2006;70:80-2.

32. Steinitz R, Parkin DM, Young JL, et al. Cancer incidence in Jewish migrants to Israel, 1961-1981. IARC Sci Publ 1989:1-311.

33. Antoniou AC, Pharoah PD, Narod S, et al. Breast and ovarian cancer risks to carriers of the BRCA1 5382insC and 185delAG and BRCA2 6174delT mutations: a combined analysis of 22 population based studies. J Med Genet 2005;42:602-3.

34. Perrin-Vidoz L, Sinilnikova OM, Stoppa-Lyonnet D, et al. The nonsense-mediated mRNA decay pathway triggers degradation of most BRCA1 mRNAs bearing premature termination codons. Hum Mol Genet 2002;11:2805-14.

35. Buisson M, Anczukow 0, Zetoune AB, et al. The 185delAG mutation (c.68_69delAG) in the BRCA1 gene triggers translation reinitiation at a downstream AUG codon. Hum Mutat 2006;27:1024-9.

36. Rashid MU, Zaidi A, Torres D, et al. Prevalence of BRCA1 and BRCA2 mutations in Pakistani breast and ovarian cancer patients. Int J Cancer 2006;119:2832-9. 